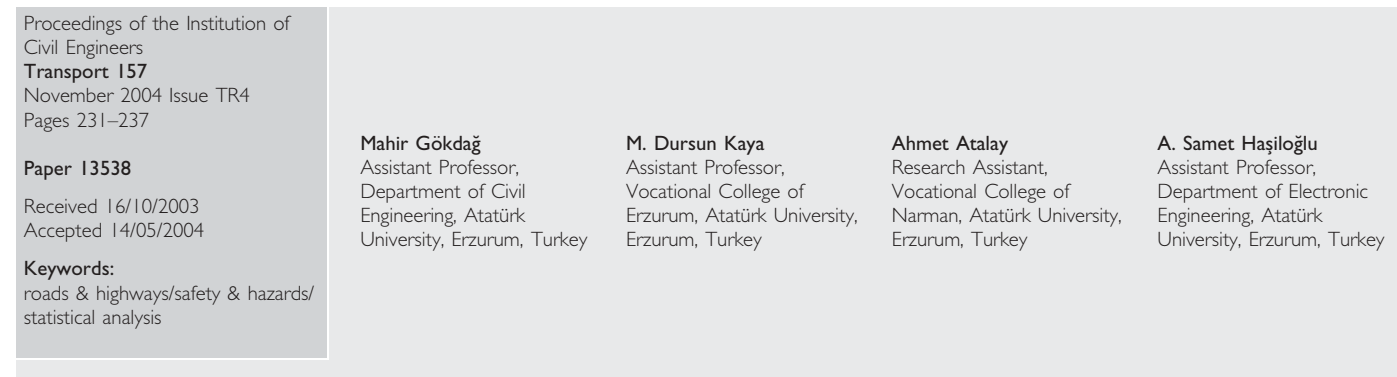

\title{
Injuries and fatalities in Turkish road traffic accidents
}

M. Gökdağ, M. D. Kaya, A. Atalay and A. S. Hașiloğlu

This study aims to describe quantitatively the injuries and fatalities from high rates of serious road traffic accidents (RTAs) in Turkey, to identify any trends during the period 1980-2000, to compare the results with those of developed countries and to evaluate the information available on possible causes with a view to identifying the most useful direction for future research. Data were obtained from the Turkish police, State Institute of Statistics, health sources and, for international comparison, from the published literature. Estimates of trends were made using linear regression. The results revealed that during the period $1980-2000$, the rates of RTAs per 100000 population and per 100000 motor vehicles increased. Deaths in each RTA increased in the short period (1980-1987) and declined during the period 1987-2000. RTA injuries during the period 1980-2000 increased steadily. Between 1980 and 2000 the severity rate (the ratio of fatalities per 1000 RTAs) decreased threefold in Turkey. Turkey's rates were compared to a number of selected countries. Further investigation requiring close collaboration between police and health authorities is therefore essential.

\section{INTRODUCTION}

The lifestyle of the people of Turkey has changed remarkably during the last 30-35 years. Gross domestic product and per capita incomes have grown rapidly, leading to increases in population, and a greater number of motor vehicles and roadway networks. Between 1980 and 2000, the population of Turkey increased at an annual average growth rate of $2 \%$. Likewise, the number of registered motor vehicles increased at an annual average growth rate of 7·6\%. ${ }^{1}$ Rising numbers of road traffic accidents (RTAs) and consequent increases in injuries and fatalities accompanied these changes. According to official reports of the State Institute of Statistics Prime Ministry RTA Statistics in Turkey, ${ }^{2}$ the RTA problem is now the second most common cause of death in the country and the leading cause of serious injuries and disabilities among adults. $^{3}$ In Turkey in 2000, 115877 people were injured, of whom 3941 (3.4\%) died. ${ }^{2}$ The problem therefore constitutes a major concern for public health and the country's economy, and a sizeable burden to Turkey's healthcare and economic resources.

In most developed countries, the problem of RTAs has attracted increasing research and safety interventions, resulting in a reduction of the size of the problem in many of these countries. $^{4-8}$

The objective of this paper is to describe quantitatively the injuries and fatalities from RTAs in Turkey, to identify any trends during the period 1980-2000 and to compare these data with the equivalent rates in developed and developing countries. Attempts have also been made to evaluate the possible causes of RTAs in Turkey using routinely collected data from the Turkish police sources. It is likely that this effort will help to establish the baseline facts about the problem of RTAs in Turkey and therefore the most useful direction that future national research and programmes on roadway traffic safety should take.

\section{MATERIAL AND METHODS}

A retrospective analysis was conducted, based on the data obtained from Turkish official reports on RTAs, RTA injuries and deaths, for people of all ages in Turkey during the period 1980-2000. High estimates for accident reporting are claimed by police authorities and are achieved by insisting that all garages and repair establishments ignore any vehicle involved in an accident unless a police report on the accident is produced, with severe penalties for both drivers and garages that fail to comply with these measures.

According to Turkish police sources, the definition of an RTA includes all traffic-related accidents that result in injury or death to road users (drivers, passengers, pedestrians, cyclists and motorcyclists); the definition of RTA injuries includes all traffic-related, non-fatal injuries; and the definition of RTA fatalities includes all traffic-related deaths that occur within 30 days from the accident. The annual crude rates of RTAs, RTA deaths and injuries (per 100000 population and per 100000 registered motor vehicles) were calculated to estimate the lay trends of the RTA problem in Turkey. The severity rates of injury and death per 1000 RTAs (the ratio of injuries and fatalities to accidents) were also calculated to quantify the risk of injury or death in RTAs. Empirical data for the rates of RTAs, RTA injuries and RTA fatalities were obtained from the Ministry of Interior Annual Statistical Report, ${ }^{2}$ R.T. General Directorate of Highways, ${ }^{9}$ State Institute of Statistics of Prime Ministry RTA Statistics, ${ }^{2}$ State Institute of Statistics of Prime Ministry Annual Statistical Reports ${ }^{1}$ and the $\mathrm{MoH}$ Annual Statistics Report. ${ }^{3}$ Population denominator data were obtained from Turkey Annual Statistical Abstract. ${ }^{10}$ The data for 
comparison were obtained from the published literature ${ }^{5,6,11}$ and the WHO Statistics Annual (1985-1996). ${ }^{12}$ Trends of RTAs, RTA deaths and injuries for 1980-2000 were estimated using linear regression analysis. The age and gender of road users injured or killed during 1980-2000 were also analysed.

Prior to 1990, Turkish police used to publish summary reports containing few details of RTA causal factors. Subsequent improvements in these reports, especially the reporting of RTA causal factors, permitted attempts to be made to determine the specific causal factors of RTAs. These factors include speeding, careless driving, personal factors (e.g. fatigue, driving under the effect of medical drugs, alcohol, etc.), environmental and vehicle conditions. ${ }^{13-15}$ Hence, the data for 1990-2000 were analysed to describe the possible factors. All data variables were processed and analysed using the statistical programmed SPSS 10. Tables and graphs were prepared using Microsoft Excel 98.

\section{RESULTS}

Motor vehicle traffic fatalities are an important public health problem in both developed and developing countries. When Turkey's fatality rates from RTAs for the period 1985-1995 were compared with the equivalent rates in a number of developed and developing countries including Portugal, Norway, USA, Australia and Kuwait, ${ }^{16}$ it could be seen that RTAs clearly presented a grave public health, social and economic problem in Turkey (Fig. 1). For the rate based on the population, the UK and Norway were the lowest of those countries; Turkey's rate was higher than those of the UK and Norway. However, the number of deaths in RTAs per 100000 persons seems to be low. When compared with the UK,
Norway, and some Eastern European countries that have witnessed a similar pattern of swift transition to market economies at the end of the 1980s, Turkey still had higher rates. For the rate based on motor vehicles for the year 1991, Turkey's rate was by far the highest and was six times higher than the mean rate of the comparison group of countries (Fig. 2).

Between 1980 and 2000 the size of the Turkish population increased at an average rate of $2 \cdot 2 \%$ per year. Likewise, the number of registered motor vehicles increased at a rate of $7 \cdot 6 \%$, averaging $7 \cdot 1 \%$ per year between 1980 and 1985 and $8.0 \%$ between 1986 and 2000. This rising trend was accompanied by an increase in the numbers of RTA injuries, but a decrease in the numbers of RTA fatalities (see Table 1).

The trend analysis of these data, using linear regression, revealed the following respective trend components: $+46 \cdot 47$ $\left(P<0.001 ; R^{2}=0.93\right)$ for RTA injuries and $-17 \cdot 7(P>0.05$; $\left.R^{2}=0 \cdot 01\right)$ for RTA fatalities. The action taken by traffic police as well as imposed speed limits reduced the number of deaths in traffic accidents, but because of the low level of seat-belt usage in Turkey and the number of the accidents not decreasing, the number of injuries increased. ${ }^{1}$

These increases were accompanied by increases in the rate of RTAs and RTA injuries but a decline in the number of RTA fatalities during the same period (see Table 2 and Figs $3-5$ ). The trend analysis of these rates, calculated on the basis of resident population and number of registered motor vehicles, revealed rising and declining trend components per 100000 population of

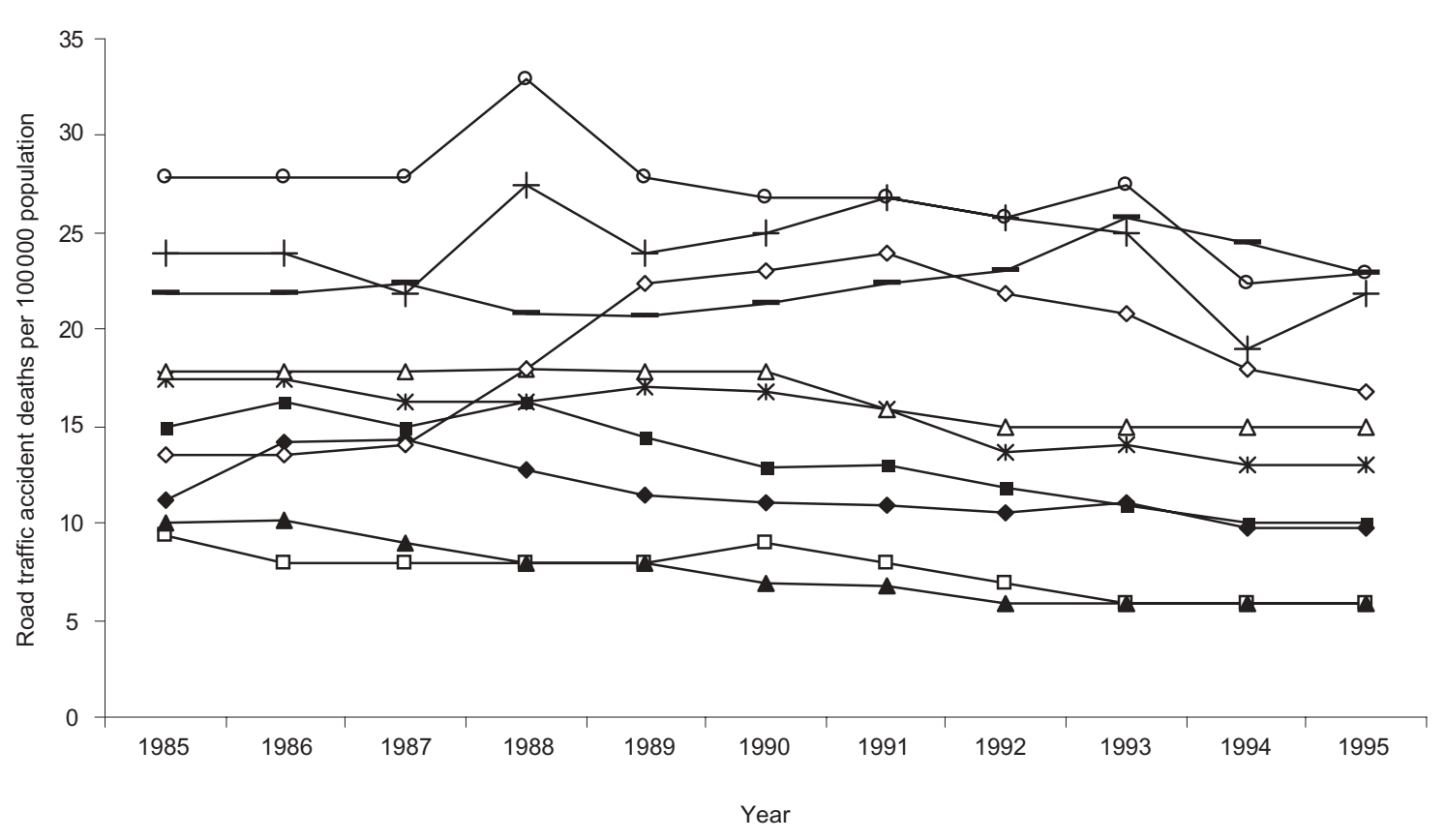

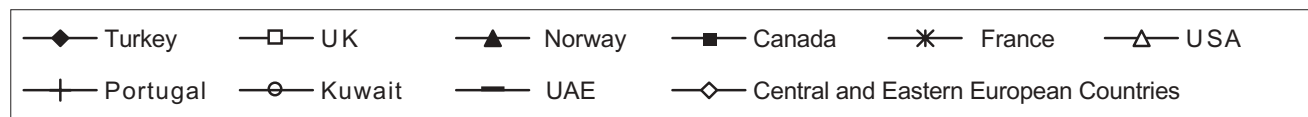




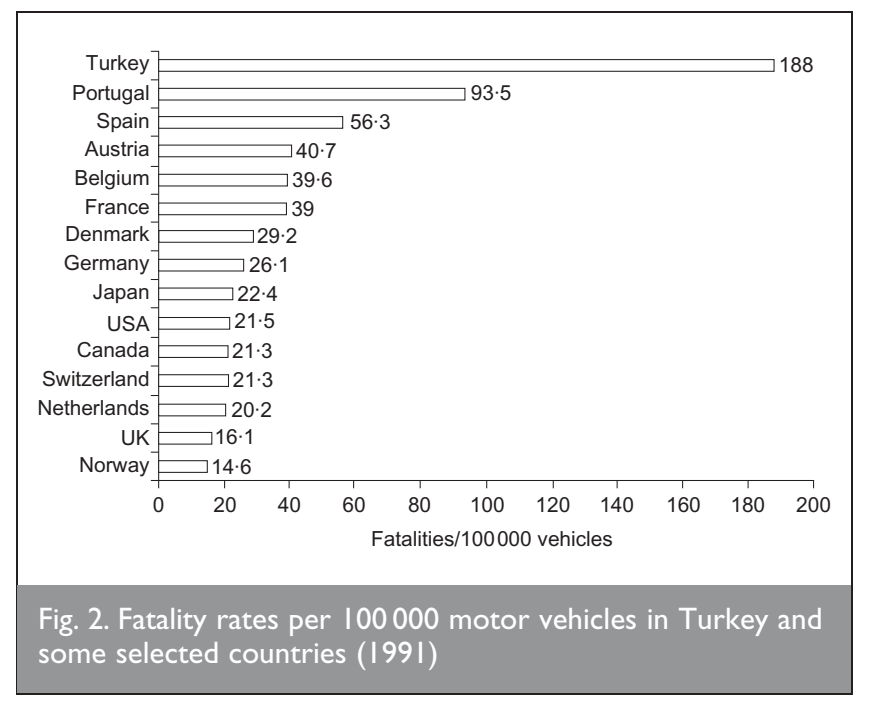

- $\quad+2.98\left(P<0.001 ; R^{2}=0.65\right)$ for RTAs

- $\quad-0.21\left(P=0.03 ; R^{2}=0.37\right)$ for RTA fatalities

- $\quad+5.70\left(P<0.001 ; R^{2}=0.79\right)$ for RTA injuries.

Per 100000 registered motor vehicles, the trend components were

- $\quad-38.17\left(P<0.005 ; R^{2}=0.34\right)$ for RTAs

- $\quad-16.06\left(P<0.001 ; R^{2}=0.91\right)$ for RTA fatalities

- $\quad-45 \cdot 37\left(P=0.025 ; R^{2}=0 \cdot 24\right)$ for RTA injuries.

Paradoxically however, except for a short period (1980-1987), these increases were accompanied by a persistent decrease in the severity of injury and the rate of death per RTA (Table 2, Figs 6 and 7). Since 1988 the severity of injury per 1000 RTAs has increased; but since 1980 the rate of death per 1000 RTAs in Turkey has been reduced threefold, and the trend components of these rates has decreased.

During the period 1980-2000 there were a total of 119380 RTA deaths in Turkey (Table 3). Of these deaths, 19.7\% were female and $80 \cdot 3 \%$ were male. Children aged $0-5$ years accounted for $10 \cdot 0 \%$ of the total RTA deaths and those aged $6-14$ years accounted for 7·4\%. Adults aged $15-44$ years accounted for a proportion of 50.6\%, which was similar to the proportion of the population in this age range (46.7\%). Of all RTA casualties during that period, motor vehicle occupants (drivers, passengers and motorcyclists) accounted for an average of $82 \%$ while pedestrians and cyclists accounted for $18 \%$. The rate of pedestrian and cyclist casualties declined slowly from 34\% in 1990 to 19\% in 1997 since bicycle use is not so common in Turkey. However, this rate increased slightly in $1997-1998$ but decreased to 18\% in 2001 (Fig. 8). NonTurkish citizens (expatriate workers and their families) accounted for an average of $3.0 \%$ and Turkish citizens accounted for an average of $97 \%$ of total RTA deaths.

The analysis of the pattern of alleged causal factors revealed some changes during the period 1990-2000 (Table 4). Careless driving was found to be the largest contributing factor for RTA deaths in Turkey over these years followed by vehicles exceeding speed limits and other factors. The percentage contribution of careless driving among other factors increased from $40 \cdot 3 \%$ in 1990 to $49 \cdot 5 \%$ in 1993 . However, the effect of this factor decreased to $39 \cdot 5 \%$ in 1994 before rising again thereafter. The contribution of speeding-the second most common cause of RTA deaths in Turkey-declined from 30.6\% in 1990 to $26 \%$ in 1994 and again to $22 \%$ in 2000 . The contribution of personal factors-the third most common cause of RTA deaths-declined, decreasing from 19.1\% in 1990 to 12.5\% in 1996 before increasing slightly to around 19.8\% in

\begin{tabular}{|cccccc|}
\hline Years & Resident population & $\begin{array}{c}\text { Number of registered } \\
\text { vehicles }\end{array}$ & Number of RTAs & Number of RTA deaths & $\begin{array}{c}\text { Number of RTA } \\
\text { injuries }\end{array}$ \\
\hline 1980 & 44737000 & 1344254 & 18500 & 24608 \\
1981 & 45540000 & 1420688 & 20293 & 4199 & 29744 \\
1982 & 46688000 & 1502370 & 22560 & 4441 & 44769 \\
1983 & 47864000 & 1610681 & 27225 & 5884 & 50521 \\
1984 & 49070000 & 1751834 & 29813 & 52586 \\
1985 & 50664000 & 1888767 & 32000 & 71264 \\
1986 & 51433000 & 2075408 & 44925 & 5680 & 80321 \\
1987 & 52561000 & 2258500 & 54001 & 7315 & 79174 \\
1988 & 53715000 & 2456688 & 53600 & 7530 & 80013 \\
1989 & 54840000 & 2659778 & 50900 & 6846 & 87693 \\
1990 & 56470000 & 2981222 & 55770 & 6332 & 90520 \\
1991 & 57291000 & 3307324 & 56536 & 6286 & 94824 \\
1992 & 58379000 & 3756137 & 58304 & 6231 & 104330 \\
1993 & 59478000 & 4380060 & 63289 & 6457 & 104717 \\
1994 & 60587000 & 4711208 & 62584 & 5942 & 114319 \\
1995 & 61706000 & 4975331 & 66029 & 6004 & 104599 \\
1996 & 62841000 & 5317565 & 62696 & 5428 & 106146 \\
1997 & 63989000 & 5810081 & 63259 & 5181 & 114552 \\
1998 & 65145000 & 6264084 & 65245 & 4935 & 109899 \\
1999 & 66304000 & 6626885 & 63515 & 4596 & 115877 \\
2000 & 67853000 & 7161379 & 64590 & 3941 & \\
& & & & & \\
\hline
\end{tabular}




\begin{tabular}{|c|c|c|c|c|c|c|c|c|}
\hline \multirow[t]{2}{*}{ Year } & \multicolumn{4}{|c|}{ RTA fatality rates } & \multicolumn{4}{|c|}{ RTA injury rates } \\
\hline & $\begin{array}{c}\text { RTA } \\
\text { fatalities }\end{array}$ & $\begin{array}{c}\text { Per } 100000 \\
\text { resident } \\
\text { population }\end{array}$ & $\begin{array}{l}\text { Per } 100000 \\
\text { resident motor } \\
\text { vehicles }\end{array}$ & $\begin{array}{c}\text { Per } 1000 \text { road } \\
\text { traffic } \\
\text { accidents }\end{array}$ & $\begin{array}{c}\text { RTA } \\
\text { injuries }\end{array}$ & $\begin{array}{l}\text { Per } 100000 \\
\text { resident } \\
\text { population }\end{array}$ & $\begin{array}{l}\text { Per } 100000 \\
\text { resident motor } \\
\text { vehicles }\end{array}$ & $\begin{array}{c}\text { Per } 1000 \\
\text { RTAs }\end{array}$ \\
\hline 1980 & 4199 & $9 \cdot 4$ & 312 & 236 & 24608 & 55 & $183 \mid$ & 1333 \\
\hline 1981 & 444 I & 9.8 & 313 & 225 & 29744 & 65 & 2093 & 1416 \\
\hline 1982 & 4884 & $10 \cdot 5$ & 325 & 217 & 35976 & 77 & 2395 & 1499 \\
\hline 1983 & 5201 & 10.9 & 323 & 189 & 44769 & 94 & 2778 & 1646 \\
\hline 1984 & 5731 & 11.7 & 327 & 192 & 50521 & 103 & 2885 & 1695 \\
\hline 1985 & 5680 & $11 \cdot 2$ & 301 & 178 & 51586 & 102 & 2731 & 1617 \\
\hline 1986 & 7315 & 14.2 & 352 & 163 & 71264 & 138 & 3434 & 1587 \\
\hline 1987 & 7530 & $14 \cdot 3$ & 333 & 139 & 80231 & 153 & 3552 & 1487 \\
\hline 1988 & 6846 & $12 \cdot 7$ & 279 & 127 & 79174 & 147 & 3222 & 1477 \\
\hline 1989 & 6332 & 11.5 & 238 & 124 & 80013 & 146 & 3011 & 1572 \\
\hline 1990 & 6286 & $11 \cdot 1$ & 211 & 112 & 87693 & 155 & 2942 & 1574 \\
\hline 1991 & 6231 & 10.9 & 188 & 110 & 90520 & 158 & 2737 & 1602 \\
\hline 1992 & 6214 & $10 \cdot 6$ & 165 & 106 & 94824 & 162 & 2525 & 1626 \\
\hline 1993 & 6457 & 11.0 & 147 & 102 & 104330 & 175 & 2382 & 1648 \\
\hline 1994 & 5942 & $9 \cdot 8$ & 126 & 95 & 104717 & 173 & 2223 & 1675 \\
\hline 1995 & 6004 & 9.7 & 121 & 91 & 114319 & 185 & 2298 & 1732 \\
\hline 1996 & 5428 & $8 \cdot 6$ & 102 & 87 & 104599 & 166 & 1967 & 1668 \\
\hline 1997 & $5|8|$ & $8 \cdot 0$ & 89 & 82 & $106 \mid 46$ & 166 & 1827 & 1677 \\
\hline 1998 & 4935 & $8 \cdot 0$ & 79 & 77 & II4 552 & 175 & 1828 & 1757 \\
\hline 1999 & 4596 & 6.9 & 69 & 72 & 109889 & 165 & 1658 & $173 \mid$ \\
\hline 2000 & 3941 & $5 \cdot 8$ & 55 & 61 & II 5887 & $17 \mid$ & 1618 & 1794 \\
\hline
\end{tabular}

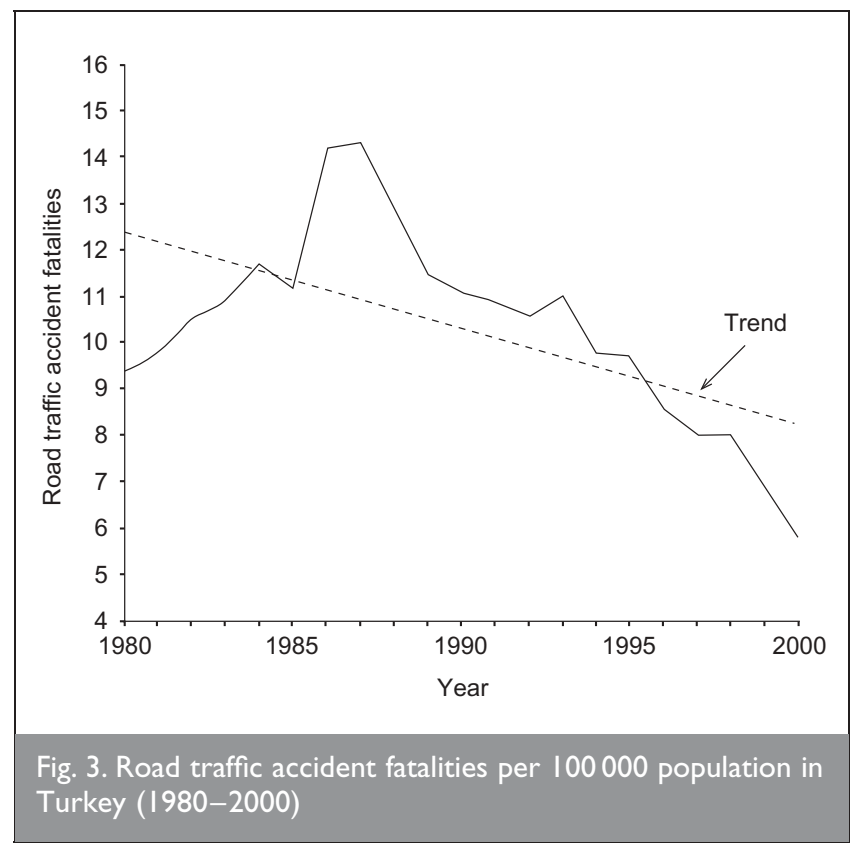

2000. Environmental and vehicle conditions appeared to be relatively less important, as both showed persistent declines. Alcohol consumption was never very high, and there was a notable percentage decrease in its contribution.

\section{DISCUSSION}

When Turkey's fatality rates from RTAs were compared with equivalent rates in other developed and developing countries, RTAs appeared to present a grave public health, social and

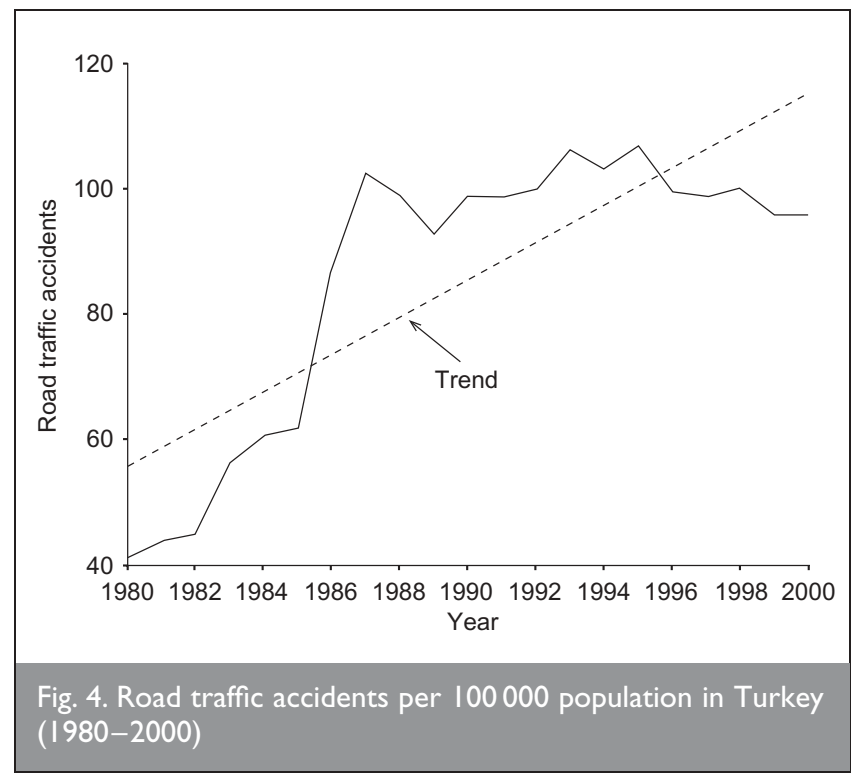

economic problem in Turkey. For the rate based on motor vehicles for the year 1991, Turkey exceeded all other countries in the list. Except for the period 1980-1987, however, the rates of RTA fatalities showed progressive declines. These declines were most probably attributable to improvements in roadway traffic engineering and design, roadway traffic controls and the provision of other safety measures on the roads. Most of the roads in Turkey are now double-lane roads, fully illuminated at night and well equipped with traffic signs in general. Moreover, from the early 1990s, many safety interventions 


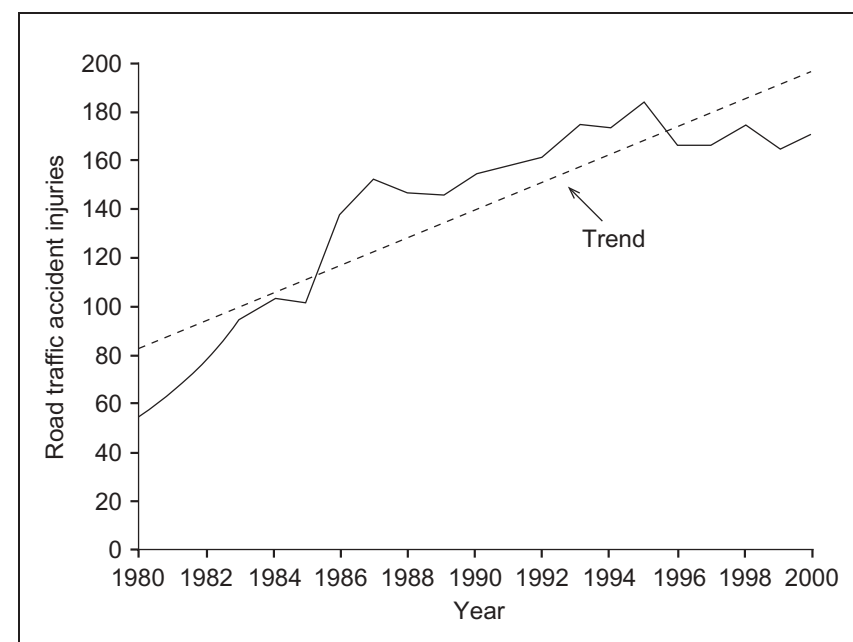

Fig. 5. Road traffic accidents injuries per 100000 population in Turkey (1980-2000)

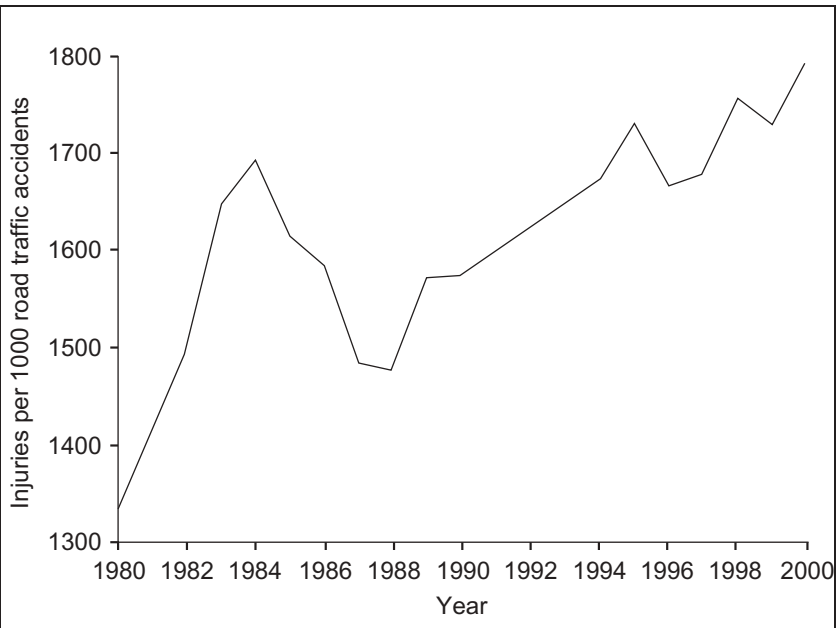

Fig. 6. Injuries from road traffic accidents per 1000 RTAs in Turkey $(1980-2000)$

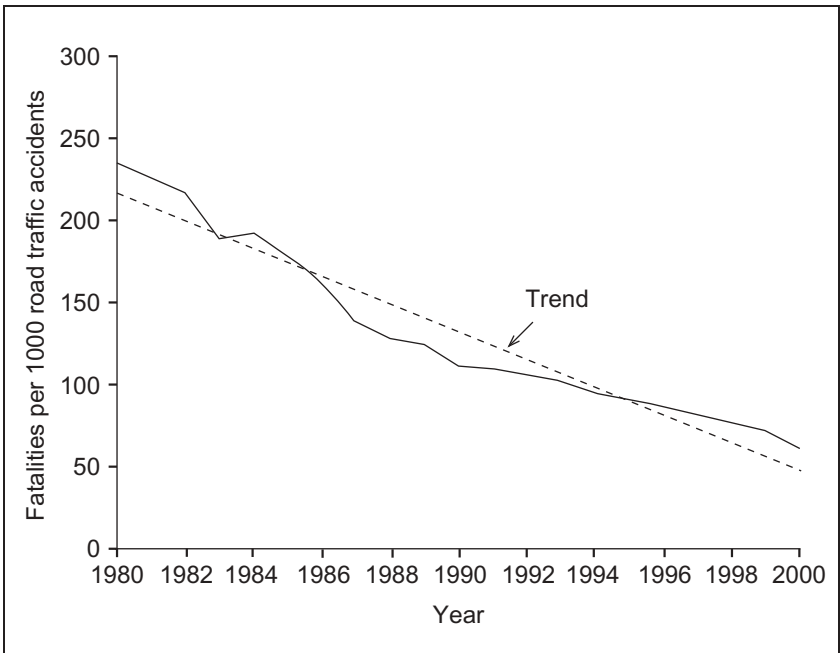

Fig. 7. Fatalities from road traffic accidents per 1000 RTAs in Turkey $(1980-2000)$ were made to curb RTAs including the enforcement of speed limits with speed radar systems, steel guard-rails along road edges, and so on. ${ }^{9}$ From 1980 the risk of death from RTAs in Turkey has progressively declined; that is, death rates per 1000 RTAs have decreased by more than threefold between 1980 and 2000. From 1989, however, the risk of injury per RTA has seen a gradual and progressive increase; that is, the severity injury rates per 1000 RTAs has increased gradually between 1989 and 2000. These patterns suggest that, whereas improvements in traffic management and roadway design have reduced the number of RTA deaths per fixed population, the number of RTA injuries per fixed population were actually increasing.

While the precise reason(s) for the increasing RTA severity in Turkey still remain unclear (due to the limitations of this study), a number of underlying factors might have contributed to it. In particular, the low level of seat-belt usage in Turkey and a failure of casualty management could be to blame.

First, despite mandatory seat-belt usage, ${ }^{17}$ the rates reported in 2000 for seat-belt use in Turkey were below 6\%. Second, smaller vehicles on the roads have replaced the older, heavier, passenger car models in Turkey. ${ }^{9}$ It is established that smaller vehicles have higher occupant injury rates because of the smaller interior space in which occupants can decelerate. The wheelbase-the distance from the front to rear axle of the vehicle-is the best predictor of differences in fatality rates due to different vehicle sizes. ${ }^{8}$ Third, the increasing difficulty in the management of serious injury following RTAs could be to blame. $^{18}$

In Turkey there is a very low level of first-aid knowledge in the community. Until recently there was a general fear of blame being attached to those who attempted to help at an accident scene. While there are well-equipped ambulances in Turkey, they are not radio dispatched and are rarely staffed with personnel knowledgeable in casualty handling or first aid. It seems reasonable to suppose that, as RTAs become increasingly complex, progressively greater skill in first aid will be needed to manage the victims of these disasters. Road engineering and hospital services have reached a high standard in Turkey but there is an important service gap still to be filled in prehospital care. Finally, it is suggested that the factors so far discussed may not be sufficient to account for the increased severity of RTAs found in this study.

The three categories of RTA causal factors with persistently high percentages (careless driving, speeding and personal factors) were most probably attributable to lack of competence and judgement on the part of the driver; but the precise underlying reasons require further investigation. The low percentage of accidents linked with alcohol is presumably reflecting its cultural disapproval, but since the rate of alcohol consumption is increasing continuously there is an accompanying increase in accidents. The contribution of drugs cannot yet be defined in the absence of a roadside test.

The analysis of the gender, age structure and road user groups of RTA casualties during 1980-2000 showed that the proportion of RTA deaths among adults from the 15-44 years age group (50.6\%) was similar to their proportion of the population (46.7\%) during 1980-2000. Children aged 0-14 


\begin{tabular}{|c|c|c|c|c|c|c|}
\hline Age group & Males & Females & Citizens & Non-citizens & Total & $\%$ \\
\hline $0-5$ & 8520 & 3475 & 11690 & 305 & 11995 & $10 \cdot 0$ \\
\hline $6-14$ & 6697 & 2087 & 8560 & 224 & 8784 & $7 \cdot 4$ \\
\hline $15-44$ & 51415 & 9041 & 59345 & $111 \mid$ & 60456 & $50 \cdot 6$ \\
\hline $45-49$ & $|735|$ & 4863 & 21507 & 707 & 22214 & 18.6 \\
\hline$>60$ & 10014 & 4007 & 13810 & 210 & 14020 & 11.8 \\
\hline Unspecified & 1910 & - & 700 & 1210 & 1910 & 1.6 \\
\hline Total & 95907 & 23473 & 115613 & 3767 & 119380 & $100 \cdot 0$ \\
\hline
\end{tabular}

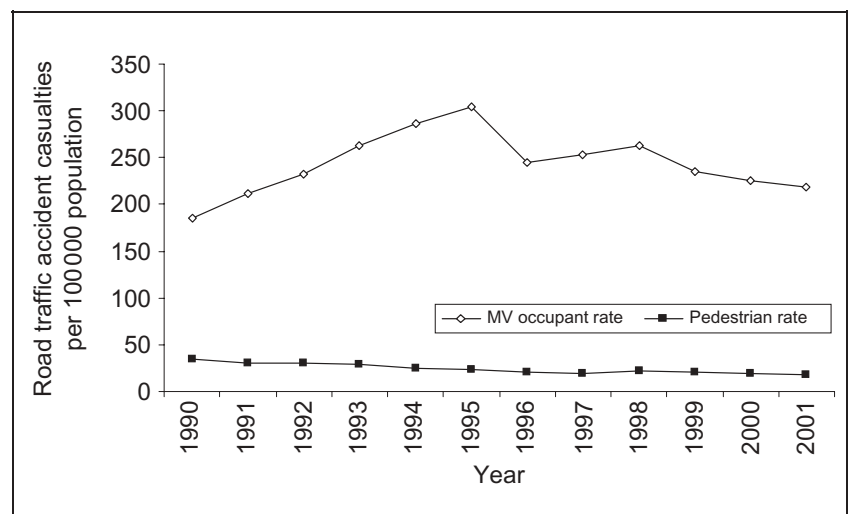

Fig. 8. Casualties per 100000 population according to roaduser groups (I990-200I)

years accounted for $17 \cdot 0 \%$ of all RTA deaths, a result that implies that children involved in RTAs in Turkey are more likely to be killed. The rate of pedestrian and cyclist casualties (per 100000 population) declined slowly from 34\% in 1990 to $18 \%$ in 2001 , which reflects the effect of the recent safety improvements of roadway design in Turkey on this user group. These improvements included the extension of median barriers, steel guard-rails along road edges, and provision of passageways at pedestrian crossings on most Turkish roads. ${ }^{9}$

\section{CONCLUSION}

The study confirmed the status of RTAs as a major and increasing cause of social, health and economic problems in
Turkey. Despite huge investment in roadway traffic infrastructure, the increase in RTAs can clearly be demonstrated. There is obviously a need to elucidate more precisely the underlying factors, and a key area to investigate is the effectiveness of traffic safety measures that have been introduced over the previous years, including enforcing speed limits on highways. ${ }^{19}$ For example, frequent police reports in Turkey suggest that the use of fixed positions for speed radar on highways and the possibility of widespread use of radar detectors that warn speeding drivers of the presence of mobile radar cameras, might have reduced the likelihood of spotting violating drivers, thereby leading to the persistent increase in the severity of RTAs.

An immediate step to control the problem would be to increase police surveillance on the roads in order to enforce traffic safety regulations (e.g. seat-belt laws and speed limits) ${ }^{20}$ and to conduct effective education campaigns on safe driving, roadway risk factors and safety precautions. These activities should be accompanied by legislation imposing severe penalties on careless driving and speeding. Another key area for reducing fatality on the roads would be the prompt and appropriate management of casualties at the roadside and during transportation to hospital and the training of traffic policemen and ambulance personnel in first aid. Finally, a computer-based surveillance system for RTA injuries is essential to support prevention strategies and to promote safety on the roads. Such a system would integrate police and hospital data to facilitate the identification of risk factors that cause RTA injuries.

\begin{tabular}{|c|c|c|c|c|c|c|c|c|}
\hline Years & $\begin{array}{l}\text { Careless } \\
\text { driving: \% }\end{array}$ & $\begin{array}{l}\text { Excessive } \\
\text { speed: \% }\end{array}$ & $\begin{array}{l}\text { Personal } \\
\text { factors: \% }\end{array}$ & $\begin{array}{c}\text { Alcohol: } \\
\%\end{array}$ & $\begin{array}{c}\text { Vehicle } \\
\text { condition: \% }\end{array}$ & $\begin{array}{l}\text { Environmental } \\
\text { factors: \% }\end{array}$ & $\begin{array}{l}\text { Unspecified } \\
\text { conditions: \% }\end{array}$ & $\begin{array}{c}\text { Total: } \\
\%\end{array}$ \\
\hline 1990 & $40 \cdot 3$ & $30 \cdot 6$ & 19.1 & $5 \cdot 3$ & $2 \cdot 1$ & - & $2 \cdot 6$ & 100 \\
\hline 1991 & 37.9 & 29.5 & $17 \cdot 2$ & $5 \cdot 1$ & $2 \cdot 0$ & 0.9 & $7 \cdot 5$ & 100 \\
\hline 1992 & $40 \cdot 2$ & $27 \cdot 4$ & 14.3 & 4.8 & 1.7 & 1.0 & 10.6 & 100 \\
\hline 1993 & 49.5 & $28 \cdot 3$ & $13 \cdot 2$ & 3.8 & 1.5 & 0.5 & $3 \cdot 2$ & 100 \\
\hline 1994 & 39.5 & $26 \cdot 3$ & 19.7 & 4.6 & 1.4 & 0.9 & 9.5 & 100 \\
\hline 1995 & $48 \cdot 1$ & $28 \cdot 5$ & 14.1 & 4.8 & 1.5 & 0.5 & $2 \cdot 5$ & 100 \\
\hline 1996 & $46 \cdot 3$ & 29.5 & 12.5 & 5.0 & 1.3 & 0.4 & 4.0 & 100 \\
\hline 1997 & 43.7 & 28.0 & 18.0 & 3.8 & 1.2 & 1.0 & 4.5 & 100 \\
\hline 1998 & 44.5 & $25 \cdot 2$ & $21 \cdot 4$ & 3.0 & $1 \cdot 2$ & 0.8 & 3.9 & 100 \\
\hline 1999 & 49.0 & $23 \cdot 3$ & $20 \cdot 0$ & $3 \cdot 3$ & 1.4 & - & 3.0 & 100 \\
\hline 2000 & $45 \cdot 5$ & $22 \cdot 3$ & 19.8 & $3 \cdot 5$ & $2 \cdot 7$ & 0.9 & $5 \cdot 3$ & 100 \\
\hline
\end{tabular}




\section{REFERENCES}

1. State Institute of Statistics. Annual Statistical Reports. SIOS, Prime Ministry Republic of Turkey, Ankara. Annual report 1980-2000.

2. State Institute of Statistics. RTA Statistics. SiOS, Prime Ministry Republic of Turkey, Ankara. Annual report 1980-2000.

3. Ministry of Health. Annual Statistical Reports of the Turkey Ministry of Health. MoH, Ankara. Annual report 1980-2000.

4. LAWREnCe J., Blincoe J. and BARBARA M. F. The economic cost of motor vehicle crashes. Department of Transport Health Statistics, 1992, 807, I.1-I.14.

5. ELVIK R. Analysis of official economic valuations of traffic accidents fatalities in 20 motorized countries. Accident Analysis and Prevention, 1995, 27, No. 2, 237-247.

6. WyatT J. P., BEARD D., GRAY A., BUSUTTIL A. and ROBERTSON C. E. Rates, causes and prevention of deaths from injuries in South-East Scotland. Injury, 1996, 27, No. 5, 337-340.

7. DiGUisepPi C., ROBERTS I. and LI L. Influence of changing travel patterns on child death rates from injury: trend analysis. British Medicial Journal, 1997, 314, No. 7082, $710-713$.

8. ROBERTSON L. S. Reducing deaths on the road: the effects of minimum safety standards, publicized crash tests, seat belts and alcohol. American Journal of Public Health, 1996, 86, No. 1, 31-34.

9. General Directorate of Highways. Annual Statistics of Turkish Highways Reports of the Turkey Republic. GDOH, Ankara. Annual report 1980-2000.

10. State InStitute of Statistics. The Turkey Annual Statistical Abstracts (TURKEY-ASA). SIOS, Prime Ministry Republic of Turkey, Ankara. 1980-2000.
11. Lama A. Road traffic safety information system in Latvia. Proceedings of the Joint Scientific Latvian-Swedish Injury Prevention Research Conference, Tukums and Riga, 1999. (in Swedish), KI Report 1999, p. 27.

12. World Health Organisation. Statistics Annual (1985-1996). WHO, Geneva, 1996.

13. ABERG L. Drinking and driving: intentions, attitudes, and social norms of Swedish male drivers. Accident Analysis and Prevention, 1993, 25, No. 3, 289-296.

14. LitTLE R. and Clontz K. Young, drunk, dangerous and driving: underage drinking and driving research findings. Journal of Studies on Alcohol, 1994, 50, No. 3, $320-330$.

15. Miller R. T. and Blincae J. L. Incidence and cost of alcohol-involved crashes in the United States. Accident Analysis and Prevention, 1994, 26, No. 5, 583-592.

16. JADAAN K. S. and BENER A. Pedestrian accidents in rich developing countries. Journal of Traffic Medicine, 1993, 21, 157-163.

17. Evans W. N. and GRAHAM J. D. Risk reduction or risk compensation? The case of mandatory safety belt use laws. Journal of Risk and Uncertainty, 1991, 4, No. 1, 61-73.

18. Bener A., BReger A. S. and Al-FAlasi A. S. Risk taking behavior in RTAs. Journal of Traffic Medicine, 1994, 22, 67-70.

19. TRANSPORTATION ReSEARCh BOARD. Designing Safer Roads: Practices for Resurfacing, Restoration, and Rehabilitation. Special Report 214, National Research Council, Washington D.C., 1987.

20. MCCARTHY P. S. Public policy and highway safety: a city-wide perspective. Regional Science and Urban Economics, 1999, 29, No. 2, 231-244.

Please email, fax or post your discussion contributions to the secretary by I May 2005: email: mary.henderson@ice.org.uk; fax: +44 (0)20 665 2294; or post to Mary Henderson, Journals Department, Institution of Civil Engineers, I-7 Great George Street, London SWIP 3AA. 